\title{
Separation of polybrominated diphenyl ethers, polychlorinated biphenyls, polychlorinated dibenzo- $p$-dioxins and dibenzo-furans in environmental samples using silica gel and florisil fractionation chromatography
}

\author{
Hanxia Liu ${ }^{\mathrm{a}}$, Qinghua Zhang ${ }^{\mathrm{a}}$, Zongwei Cai ${ }^{\mathrm{a}}{ }^{\mathrm{b}}, \mathrm{An} \mathrm{Li}^{\mathrm{c}}$, Yawei Wang ${ }^{\mathrm{a}}$, Guibin Jiang ${ }^{\mathrm{a}, *}$ \\ ${ }^{a}$ State Key Laboratory of Environmental Chemistry and Ecotoxicology, Research Center for Eco-Environmental Sciences, \\ Chinese Academy of Sciences, Beijing 100085, PR China \\ b Dioxin Analysis Laboratory, Hong Kong Baptist University, Kowloon, Hong Kong SAR, China \\ c School of Public Health, University of Illinois at Chicago, 2121 West Taylor Street, MC-922, Chicago, IL 60612-7260, USA
}

Received 22 July 2005; received in revised form 3 October 2005; accepted 4 October 2005

Available online 21 November 2005

\begin{abstract}
A comprehensive procedure was established for the fractionation of solvent-extracted environmental samples into three fractions containing polybrominated diphenyl ethers (PBDEs), polychlorinated biphenyls (PCBs) and polychlorinated dibenzo-p-dioxins and dibenzo-furans (PCDD/Fs), respectively. The procedure includes multi-layer silica gel chromatography to separate PBDEs from PCBs and PCDD/Fs, and subsequent separation of PCBs from PCDD/Fs using a florisil column. The numbers of congeners involved were 16, 19, and 17, for PBDEs, PCBs, and PCDD/Fs, respectively. The separation of the three chemical groups overcomes the potential mutual interferences, which are difficult to avoid even by the use of high resolution mass spectrometer (HRMS). In addition, this procedure efficiently eliminates most interfering substances from sample matrices for the subsequent instrumental analyses. The method was validated using mixed chemical standards, and applied for the analysis of environmental samples including sediment, sewage sludge and fish tissue. All the recoveries are within the acceptable ranges specified in the USEPA standard methods. (C) 2005 Elsevier B.V. All rights reserved.
\end{abstract}

Keywords: PBDEs; PCBs; PCDD/Fs; Silica gel chromatography; Florisil; HRGC/HRMS

\section{Introduction}

Polychlorinated dibenzo- $p$-dioxins and dibenzo-furans (PCDD/Fs) are highly toxic compounds formed as by-products during chemical and combustion processes. Polychlorinated biphenyl (PCBs) and polybrominated diphenyl ethers (PBDEs) have been manufactured in large quantities and are contained in many industrial and consumer products [1,2]. It was reported that both PCBs and PBDEs possess dioxin-like activity, and all of them are toxic, endocrine disrupting, and probably carcinogenic [3,4]. Because all these three groups of pollutants are ubiquitous, it is likely that they co-exist in most environmental matrices [5-9]. Therefore, simultaneously monitoring of their levels in environmental samples is highly desired in order to protect human health.

\footnotetext{
* Corresponding author. Fax: +86 1062849179.

E-mail address: gbjiang@mail.rcees.ac.cn (G. Jiang).
}

US EPA has issued separate standard methods for the analysis of PBDEs, PCBs, and PCDD/Fs in environmental samples; for example, Methods 1614 (draft), 1668A, 1613B, and 8290 for high resolution gas chromatography coupled with high resolution mass spectrometry (HRGC/HRMS), and Methods 8082, $8280 \mathrm{~A}$ for high resolution gas chromatography coupled with low resolution mass spectrometry (HRGC/LRMS) or electron capture detector $(\mathrm{ECD})$. Because the extraction procedures required by these methods are not specific to any of the three analyte groups, they can be extracted from the sample with a single extraction process. In view of that, simultaneous analysis of these three toxic chemical families in one single extracted sample is feasible.

Due to the extremely low levels of the target compounds and the large number of interfering substances, analytical methodologies for these three chemical groups are especially difficult. To overcome these analytical difficulties, either a highly selective detection or tedious cleanup or even both are demanded [10]. Thus, an isotopic dilution technique coupled with HRGC/HRMS 
has been used to provide a reliable quantification and to accurately determine the concentrations of these analytes. However, the interference cannot be completely resolved even by using HRGC/HRMS due to the co-elution of these compounds on different types of columns with the same isobaric ions [10-12]. For example, PCB180 and BDE47 were found to co-elute from a capillary GC column, and their separation based on mass-tocharge ratio $(\mathrm{m} / \mathrm{z})$ requires a $\mathrm{MS}$ resolution >23,500 [10], which is beyond the resolutions routinely used by conventional HRMS systems such as the one available in our laboratory. Pirard et al. eliminated the potential interferences between PCBs and PBDEs through increasing the selectivity of the detector [9]. They confirmed that combination of electron ionization (EI) and tandem in time mass spectrometry offers the accuracy of EI-HRMS. However, separating the targeted chemical groups before instrumental analysis is highly beneficial to laboratories without MS detectors with high resolution. Because ECD is non-selective, not only the interferences from sample matrix are difficult to avoid, but also the interfering among the target compounds can be substantial, especially when their concentration levels differ dramatically. A few studies were published regarding to the simultaneous analysis of these three toxic chemical families in a single sample [7-9]. But none of them had completely separated PBDEs from PCBs although it is known that they may interfere with each other.

In this study, a comprehensive sample fractionation procedure was successfully developed to separate PBDEs, PCBs and
PCDD/Fs into three fractions. This procedure not only eliminates much of the interferences from matrix substances, but also diminishes the possibility of mutual interference among the three chemical families during instrumental analysis with the use of any detector.

\section{Materials and methods}

\subsection{Chemicals}

All solvents were pesticide residue grade and were purchased from Fisher. Silica gel $(0.063-0.100 \mathrm{~mm})$ was obtained from Merck. Basic alumina (150 mesh) was purchased from Aldrich. Florisil (60-100 mesh) was obtained from Riedel-de Haën. Bio-Beams SX-3 was purchased from Bio-Rad. Standard solutions of PCDD/Fs (1613-LCS, 1613-IS) [13], PCBs (68a-LCS, 68a-IS) [14], and PBDEs ( ${ }^{13} \mathrm{C}-$ labeled MBDE-47, 99 and 153) were obtained from Wellington Laboratories. The targeted PCBs ranged from di- to deca-chlorinated congeners with IUPAC number 15, 19, 37, 52, 54, 77, 81, 101, 104, 105, $114,118,123,126,138,155,156,157,167,169,188,189,194$, 202, 205, 206, 208, and 209. EO5103 (2500 ng/mL), a mixture of native BDEs 17, 28, 47, 66, 71, 85, 99, 100, 138, 153, 154, 183, 190, and 209 was purchased from Cambridge Isotope Laboratories. Standard reference material SRM 1941b (marine sediment) was obtained from National Institute of Standards and Technology (NIST). Fish tissue and sewage sludge were collected from

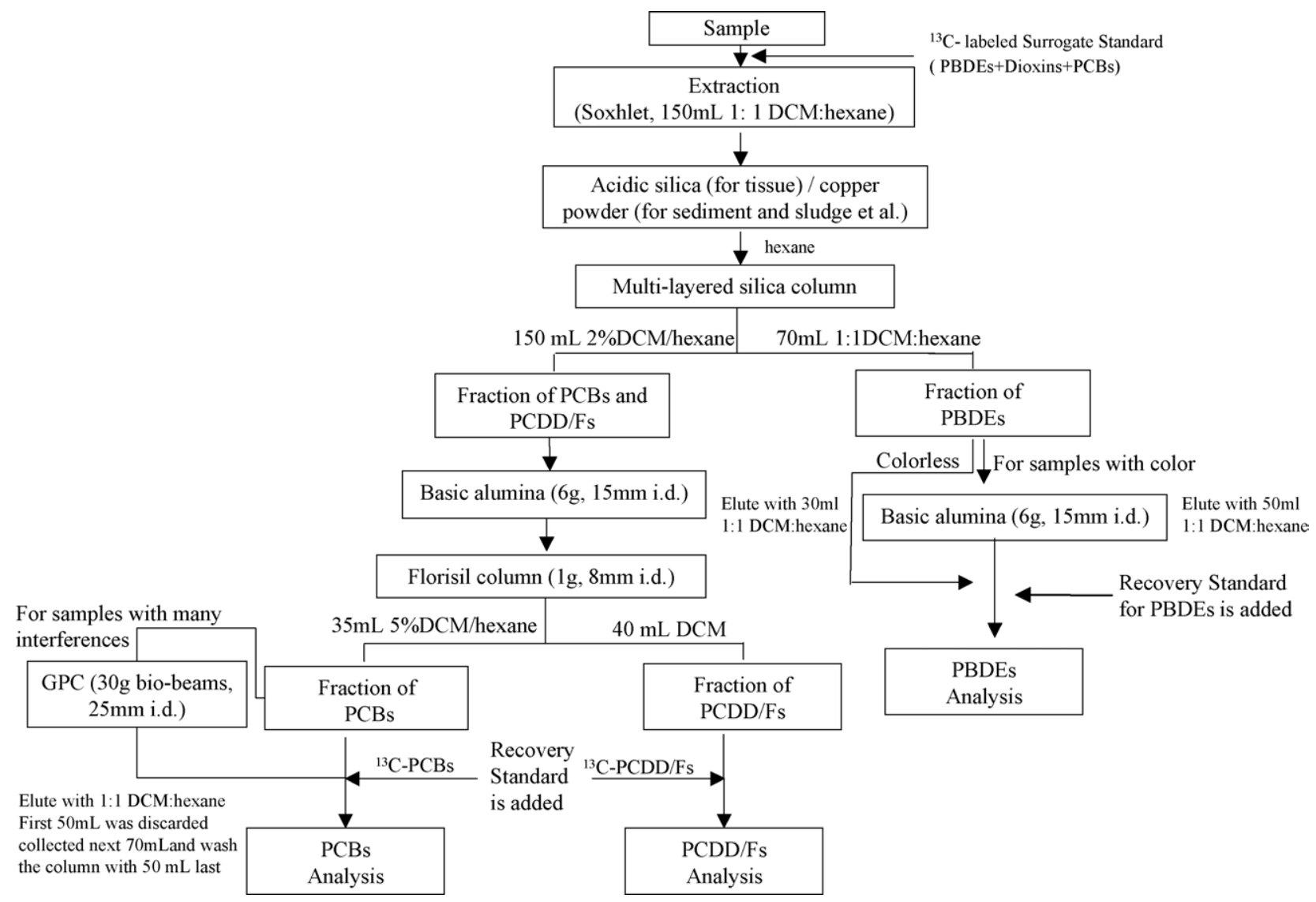

Fig. 1. Procedure for separating PBDEs, PCBs and PCDD/Fs. 
Taihu Lake and a wastewater treatment plant in Pingdingshan, Henan Province of China, respectively. Detailed sample collection and extraction procedures were described elsewhere [15].

\subsection{Sample preparation and purification}

The analytical procedure was presented in Fig. 1. Briefly, freeze-dried environmental samples were spiked with ${ }^{13} \mathrm{C}$ labeled surrogate standards prior to a $24 \mathrm{~h}$ Soxhlet extraction with 1:1 dichloromethane (DCM):hexane or other solvents. After the extraction, acidic silica and copper powder were added to remove lipid and sulphur in the samples, respectively. The extract was concentrated by a rotary evaporator, and the residue was dissolved in hexane. These extraction and concentration steps were not needed during the development of the chromatographic cleanup procedure, for which a solution of mixed chemical standards was used.

The concentrated extract was sequentially subjected to multilayer silica gel, basic alumina, florisil chromatography columns and gel permeation chromatography (GPC) for further cleanup and being separated into three groups of chemicals. The multilayer silica gel column (glass column with $15 \mathrm{~mm}$ inner diameter and $30 \mathrm{~cm}$ long) was packed from bottom to top with $1 \mathrm{~g}$ activated silica, $4 \mathrm{~g}$ basic silica $(1.2 \%$, w/w), $1 \mathrm{~g}$ activated silica, $8 \mathrm{~g}$ acidic silica (30\%, w/w), $1 \mathrm{~g}$ activated silica, $2 \mathrm{~g} \mathrm{AgNO}_{3}$ silica $(10 \%, \mathrm{w} / \mathrm{w})$ and $4 \mathrm{~g}$ anhydrous sodium sulphate. The preparation of the materials was according to EPA 1613B, 1668A and JIS K 0311/2. The GPC was packed with $30 \mathrm{~g}$ SX-3 bio-beams using 1:1 DCM:hexane as the elution solvent. The absorbent was immerged in 1:1 DCM:hexane while not being used. Elution of the sample was carried out at a rate of about $1 \mathrm{~mL} / \mathrm{min}$. The eluted sample was collected in three fractions, which were concentrated to $10 \mu \mathrm{L}$. Then, ${ }^{13} \mathrm{C}$-labeled internal standards, 1668A-IS (for PCBs and PBDEs fractions) and 1613-IS (for PCDD/Fs), were added prior to the GC injection.

\subsection{Instrumental analysis}

The quantification was performed on an Agilent 6890 gas chromatography coupled with an Autosepc Ultima high resolution mass spectrometer with an electron impact (EI) ion source. The HRMS was operated in SIM mode at $R \geq 10,000$. Exactly $1 \mu \mathrm{L}$ of sample solution was injected with a CTC PAL autosampler in splitless mode into a capillary column. Helium was the carrier gas with a constant flow of $1.2 \mathrm{~mL} / \mathrm{min}$. The other instrumental conditions for the analysis of PBDEs, PCBs and PCDD/Fs are listed in Table 1.

\section{Results and discussion}

\subsection{Separation of PBDEs from $P C B$ s and $P C D D / F$ s using multi-layer silica column}

Because PBDEs have different chemical structures from PCBs and PCDD/Fs [16] and thus different polarities, it is possible to separate PBDEs from PCBs and PCDD/Fs by using column chromatography. Separation of PBDEs from PCBs and

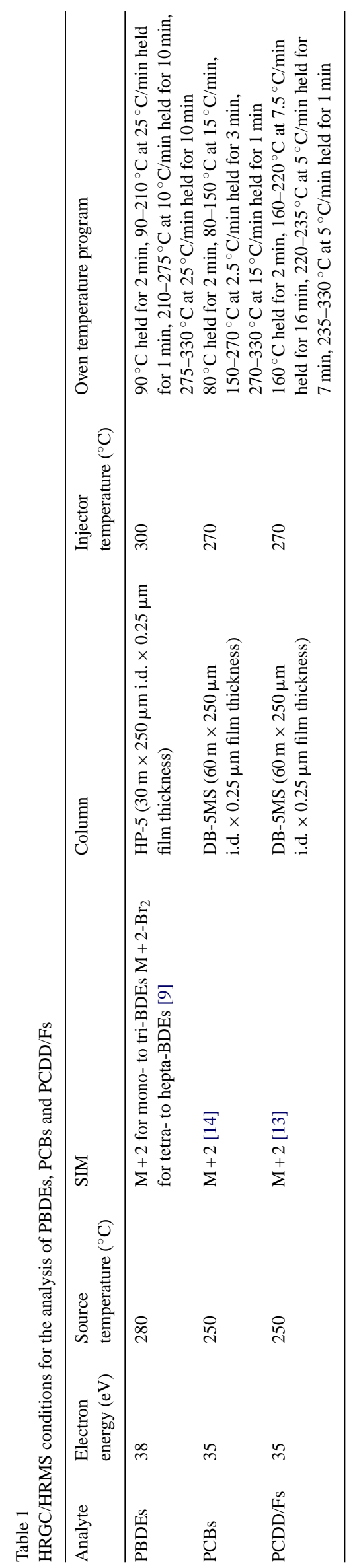




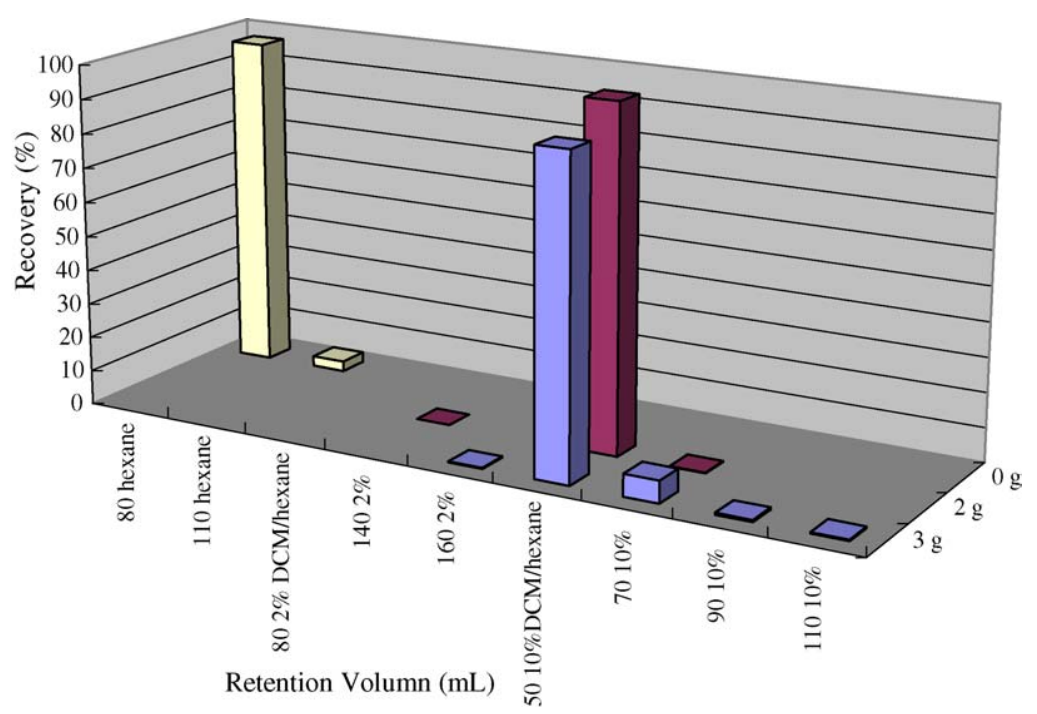

Fig. 2. Elution of BDE-47 from multi-layer silica column with different mass of silver nitrate silica.

PCDD/Fs was investigated by using different chromatography columns with various solvent mixtures. The results showed that basic alumina and florisil chromatography columns, when used alone, could not separate PBDEs and PCBs effectively. Silica gel, the most widely used sorbent in sample cleanup, was found to retain PBDEs more strongly than other sorbents. This observation is in agreement with the capabilities of neutral silica to fractionate PCBs from PBDEs previously described [17]. Therefore, the separation of PBDEs from PCBs and PCDD/Fs was then further investigated using a multi-layer silica gel chromatography column.

The results show that silver nitrate $\left(\mathrm{AgNO}_{3}\right)$ silica in the multi-layer silica column plays an important role in the process of separation. Without $\mathrm{AgNO}_{3}$ silica layer, all PBDEs were eluted mostly along with the other two chemical groups within the first $80 \mathrm{~mL}$ hexane. When $2 \mathrm{~g} \mathrm{AgNO}_{3}$ silica was packed in the multi-layer silica column, PBDEs were not eluted out even with $150 \mathrm{~mL}$ hexane. With $3 \mathrm{~g} \mathrm{AgNO}_{3}$ silica, $160 \mathrm{~mL}$ of $2 \%$ DCM in hexane could not elute PBDEs out from the multilayer silica column, and that for column with $2 \mathrm{~g} \mathrm{AgNO}_{3}$ silica was $140 \mathrm{~mL} 2 \%$ DCM in hexane. Elution curve of BDE-47 on multi-layer silica column with different mass of $\mathrm{AgNO}_{3}$ silica is presented in Fig. 2. However, PCBs and PCDD/Fs could be eluted out almost completely with those amounts of solvents. The result showed that increasing the amount of $\mathrm{AgNO}_{3}$ silica in the multi-layer silica column would strengthen the retention of PBDEs to a larger extent than those of PCBs and PCDD/Fs. Moreover, $\mathrm{AgNO}_{3}$ silica was found to be a very efficient sulphur removing agent [18-20]. Considering both the performance and cost, multi-layer silica columns with $2 \mathrm{~g} \mathrm{AgNO}_{3}$ silica was more preferable.

In general, almost all PCBs and PCDD/Fs were eluted prior to the elution of PBDEs. The earlier elution of PCBs and PCDD/Fs than PBDEs may indicate stronger interactions between PBDEs and silica gel sorbent. By using various solvent mixtures as the eluents, the elution behaviors of three chemical families were studied on multi-layer silica chromatography column. For PCBs, the heavier congeners were eluted earlier thus would not overlap with PBDEs. To efficiently elute lower chlorinated biphenyls such as PCB15 efficiently, hexane, 2\% DCM in hexane, and 5\% DCM in hexane were tested. After cutting off the collection of PCBs and PCDD/Fs, $10 \%, 20 \%$, and 50\% DCM in hexane were

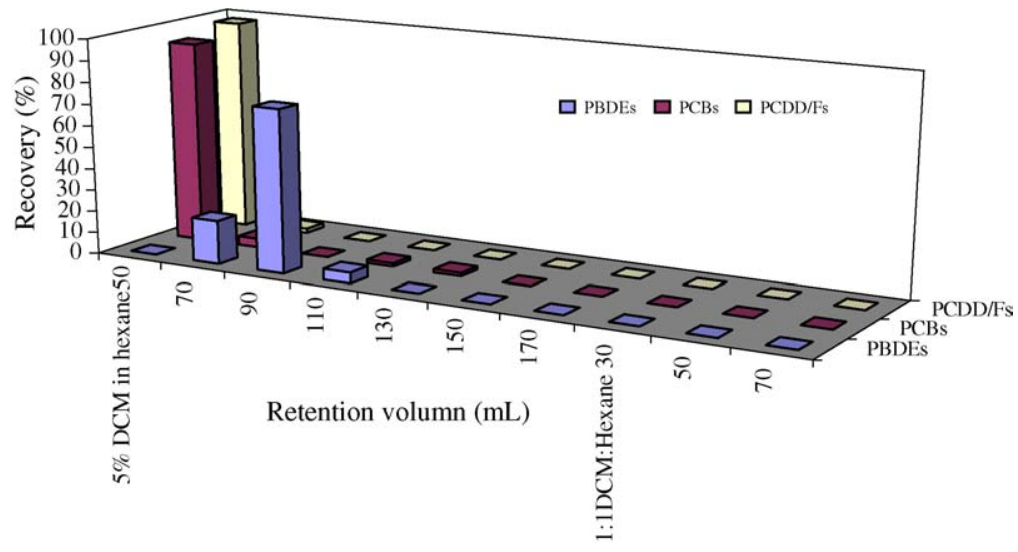

Fig. 3. Elution pattern on multi-layered silica column by using 5 and $50 \%$ DCM in hexane as eluents. 


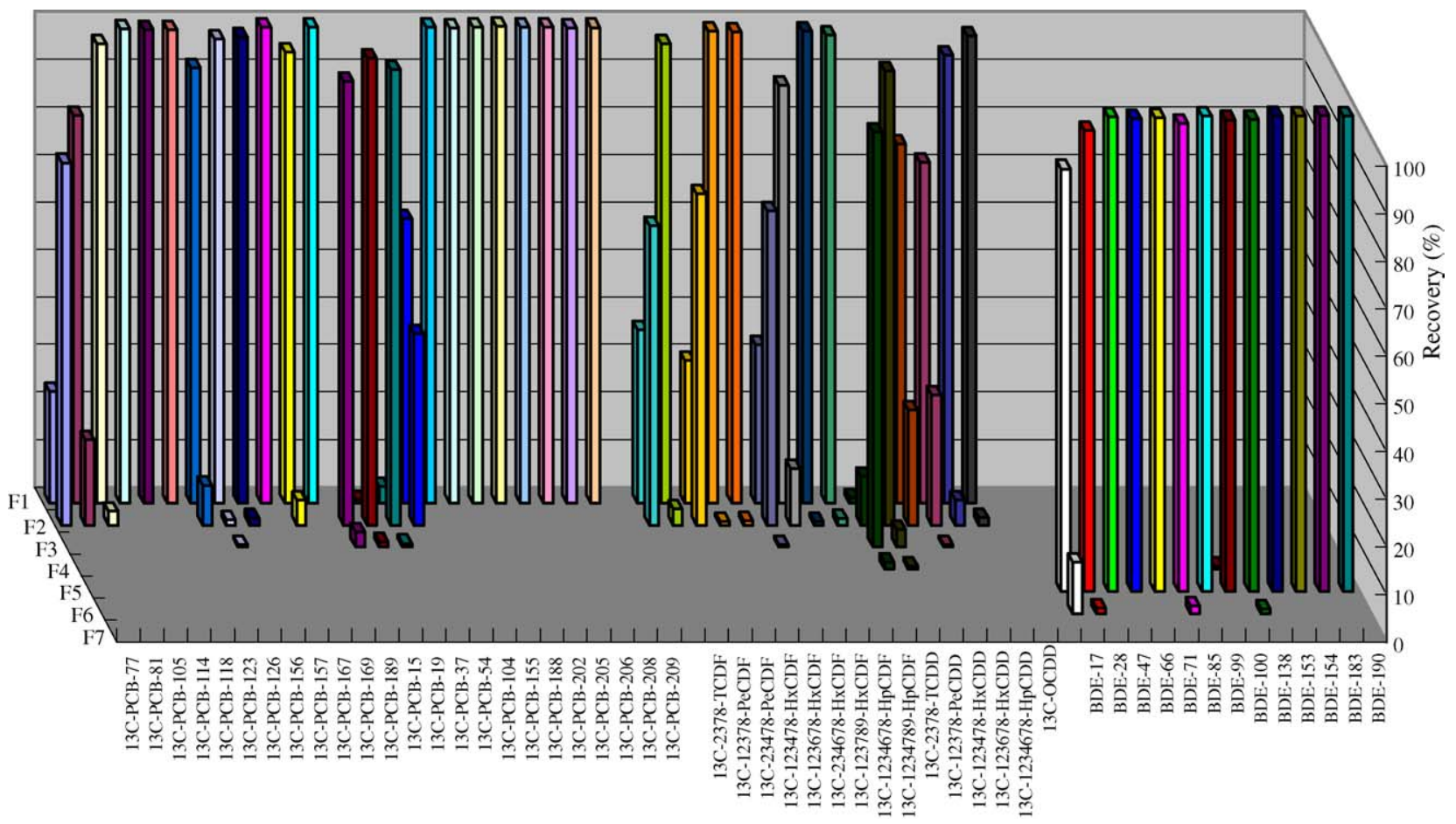

Fig. 4. Elution of PCBs, PCDD/Fs and PBDEs on multi-layer silica column with $2 \mathrm{~g}$ silver nitrate silica.

studied to elute PBDEs. The results showed that lower chlorinated biphenyls could not be eluted completely by using $130 \mathrm{~mL}$ hexane, while PBDEs could be eluted by 5\% DCM in hexane along with PCBs and PCDD/Fs (Fig. 3). However, 2\% DCM in hexane could separate PBDEs from PCBs and PCDD/Fs efficiently. As shown in Fig. 4, PCBs and PCDD/Fs could be eluted out of the multi-layer silica column in the first $110 \mathrm{~mL}$ of $2 \%$ DCM in hexane. PBDEs were not eluted out almost until the eluting solvent was changed to $10 \%$ DCM in hexane, indicating separation of PBDEs from PCBs and PCDD/Fs can be achieved by using the multi-layer silica column in the process of routine cleanup with lower than $1.5 \%$ overlap. From the elution pattern, we found that PBDEs 28, 100, 154 were more weakly sorbed on multi-layer silica column than the other congeners. In addition, all 10\%, 20\% and 50\% DCM in hexane eluted PBDEs completely from the column with the volume of 70,50 and $30 \mathrm{~mL}$, respectively. It is necessary to choose the eluting solvent for PBDEs in the analysis of environmental samples, based on the type and levels of the interfering substances in the sample.

Based on these results, efficient separation of PBDEs from PCBs and PCDD/Fs could be achieved by using multi-layer silica column packed with a total of $17 \mathrm{~g}$ silica gel including $2 \mathrm{~g}$ $\mathrm{AgNO}_{3}$ silica. PCBs and PCDD/Fs fractions were collected in $150 \mathrm{~mL}$ of $2 \%$ DCM in hexane and PBDEs were eluted with $70 \mathrm{~mL} 50 \%, 100 \mathrm{~mL} 20 \%$, or $150 \mathrm{~mL} \mathrm{10 \%} \mathrm{DCM} \mathrm{in} \mathrm{hexane.}$

\subsection{Separation of PCBs from PCDD/Fs using a small florisil column}

After the separation of PBDEs from PCBs and PCDD/Fs, further separation of PCBs and PCDD/Fs was performed. Activated carbon chromatography columns with toluene have been widely used in the separation of PCBs and PCDD/Fs [18]. However, the performance of activated carbon chromatography column was found to be inconsistent due to the inconsistent sorbent packing. In this study, a small column $(150 \mathrm{~mm} \times 8 \mathrm{~mm}$ i.d. $)$ containing $1 \mathrm{~g}$ florisil sorbent was selected to achieve the separation according to the good performance in the separation of PCBs and PCDD/Fs of florisil [21-23]. Thirty-five millilitres of 5\% DCM in hexane was selected to elute PCBs, followed by $40 \mathrm{~mL}$ of $100 \%$ DCM for the elution of PCDD/Fs.

For samples rich in high molecular weight interferences, such as sludge, sediment and tissue, GPC is very necessary to cleanup the PCB fraction [24,25]. High molecular weight interferences that cause degradation of GC column performance can be efficiently removed by using GPC [13].

\subsection{Method validation}

Method performance was evaluated by triplicate analyses of mixed standards including 1613-LCS, 68A-LCS and EO5103, using 1613-IS, 68A-IS and ${ }^{13} \mathrm{C}$-labeled MBDE 47, 99 and 153 as internal standards. The average recoveries and relative standard deviation of PCBs, PCDD/Fs and PBDEs are listed in Table 2. These results met the criteria of acceptance specified in the USEPA methods 1613B, 1668A and 1614-draft.

\section{Table 2}

Average recoveries and relative standard deviation (R.S.D.) $(n=3)$ of PCBs, PCDD/Fs and PBDEs of mixture of 1613-LCS, 68A-LCS and EO 5103

\begin{tabular}{lll}
\hline & Average recoveries (\%) & R.S.D. (\%) \\
\hline PCBs & $62-105$ & $0.7-22.0$ \\
PCDD/Fs & $72-120$ & $0.1-27.4$ \\
PBDEs & $60-101$ & $6.5-29.6$ \\
\hline
\end{tabular}


Table 3

Background contamination of PCBs and PBDEs in method blanks $(n=3)$

\begin{tabular}{|c|c|c|}
\hline Congeners & Average (pg/g) & S.D. \\
\hline PCB-77 & 0.4 & 0.06 \\
\hline PCB-81 & ND & - \\
\hline PCB-105 & 0.3 & 0.24 \\
\hline PCB-114 & ND & - \\
\hline PCB-118 & 9.1 & 6.53 \\
\hline PCB-123 & 12.1 & 17.16 \\
\hline PCB-126 & ND & - \\
\hline PCB-156 & ND & - \\
\hline PCB-157 & ND & - \\
\hline PCB-167 & ND & - \\
\hline PCB-169 & ND & - \\
\hline PCB-189 & ND & - \\
\hline PCB-28 & 22.7 & 2.16 \\
\hline PCB-52 & 3.6 & 0.46 \\
\hline PCB-101 & 2.7 & 0.25 \\
\hline PCB-138 & 1.5 & 0.17 \\
\hline PCB-153 & 1.5 & 0.32 \\
\hline PCB-180 & ND & - \\
\hline PCB-209 & 0.7 & 0.07 \\
\hline BDE-17 & 1.8 & 0.99 \\
\hline BDE-28 & 1.9 & 0.91 \\
\hline BDE-47 & 10.2 & 7.20 \\
\hline BDE-49 & 2.0 & 1.87 \\
\hline BDE-66 & 1.7 & 0.43 \\
\hline BDE-71 & 1.2 & 0.45 \\
\hline BDE-77 & 0.4 & 0.61 \\
\hline BDE-85 & ND & - \\
\hline BDE-99 & 5.2 & 2.52 \\
\hline BDE-100 & 0.7 & 0.78 \\
\hline BDE-119 & ND & - \\
\hline BDE-126 & ND & - \\
\hline BDE-138 & ND & - \\
\hline BDE-153 & 1.0 & 1.71 \\
\hline BDE-154 & ND & - \\
\hline BDE-183 & 1.0 & 1.79 \\
\hline
\end{tabular}

The above method was applied in the analysis of sediment samples. It was observed that PBDEs could be eluted together with the other two families even by hexane if the layer of acidic silica was nearly overloaded, indicating severe matrix effect on separation efficiency. In these cases, another multi-layer silica column was needed to clean the sample before the separation of the three groups. In the first multi-layer silica column, $70 \mathrm{~mL}$ $50 \%$ DCM in hexane was used as the eluent, and all the eluted solution was colleted and concentrated. Then, the second multilayer silica column was used with the procedure described in the previous section. Thus, in order to achieve a complete separation of PBDEs from PCBs and PCDD/Fs, two multi-layer
Table 5

PCB concentrations in standard reference material (NIST SRM 1941b)

\begin{tabular}{lcll}
\hline Congeners & $\begin{array}{l}\text { Certified } \\
\text { concentrations } \\
(\mu \mathrm{g} / \mathrm{kg})\end{array}$ & $\begin{array}{l}\text { Concentrations } \\
\text { in this study } \\
(\mu \mathrm{g} / \mathrm{kg})\end{array}$ & Z-score \\
\hline CB 28 & $4.52 \pm 0.57$ & 4.54 & 0.03 \\
CB 52 & $5.24 \pm 0.28$ & 5.27 & 0.11 \\
CB 101 & $5.11 \pm 0.34$ & 5.08 & 0.09 \\
CB 105 & $1.43 \pm 0.10$ & 1.40 & 0.30 \\
CB 118 & $4.23 \pm 0.19$ & 4.24 & 0.05 \\
CB 138 & $3.60 \pm 0.28$ & 4.08 & 1.71 \\
CB 153 & $5.47 \pm 0.32$ & 5.46 & 0.03 \\
CB 156 & $0.507 \pm 0.090$ & 0.40 & 1.19 \\
CB 180 & $3.24 \pm 0.51$ & 3.28 & 0.08 \\
CB 209 & $4.86 \pm 0.45$ & 5.96 & 2.44 \\
\hline
\end{tabular}

silica columns were needed for matrixes with large quantities of interferences.

It should also be noted that inclusive solvent exchange is important in order to achieve an efficient separation of PBDEs from the other two chemical groups. This is especially true if toluene is used in the extraction process. It was found that the extract with approximate $2 \mathrm{~mL}$ toluene could elute down all the three groups of chemicals together from the multi-layer silica column within the first $30 \mathrm{~mL}$ hexane. Therefore, toluene should be completely replaced by hexane prior to loading the sample into the multi-layer silica column.

The method applicability was further examined using sewage sludge and fish tissue samples. A standard reference material, SRM1941b, was also analyzed as part of the international intercalibration study on PBDEs organized by NIST in 2004. Three method blanks were analyzed along with the samples. Seventeen 2,3,7,8-subsituted chlorinated congeners of PCDD/Fs, 12 WHO toxic congeners of PCBs, 6 indicator PCBs (PCB 28, 52, 101, 138, 153 and 180) and PCB 209 as well as 16 PBDEs (BDE17, $28,47,49,66,71,77,85,99,100,119,126,138,153,154$ and 183 ) were quantitatively determined. The background contamination of PCBs and PBDEs in method blanks is listed in Table 3. Recoveries and concentrations of PCBs, PCDD/Fs and PBDEs in environmental samples are depicted in Table 4. Congenerspecific concentrations of PCBs in SRM1941b is summarized in Table 5 and compared with the certified values. The results for PCBs and PBDEs were satisfactory, with $Z$-scores being $<1$ for all congeners of PBDEs analyzed. To simplify the cleanup procedure, a single multi-layer silica column was used for each sample. All recoveries met the criteria specified in US-EPA methods 1668A, 1613B and 1614-draft for PCBs, PCDD/Fs, and PBDEs, respectively.

Table 4

Recoveries and concentrations of PCBs, PCDD/Fs, and PBDEs in environmental samples

\begin{tabular}{|c|c|c|c|c|c|c|}
\hline & \multicolumn{3}{|c|}{ Concentrations $\mathrm{s}^{\mathrm{a}}$} & \multicolumn{3}{|c|}{ Recovery (\%) } \\
\hline Sewage sludge & 1.63 & 20.66 & 5386 & $96-139$ & $64-87$ & $67-107$ \\
\hline Fish tissue & 0.99 & 2.06 & 4911 & $94-122$ & $46-96$ & $47-75$ \\
\hline
\end{tabular}

\footnotetext{
${ }^{a}$ Concentrations are in $\mathrm{pg}$ WHO-TEQ/g dw for PCBs and PCDD/Fs, and in $\mathrm{pg} / \mathrm{g} \mathrm{dw}$ for PBDEs.
} 


\section{Conclusion}

A comprehensive procedure was established for determination of PBDEs, PCBs and PCDD/Fs in environmental samples. Multi-layer silica gel chromatography with silver nitrate silica was used firstly to separate PBDEs from PCBs and PCDD/Fs. The separation of the three chemical groups overcomes the potential mutual interferences to determine more accurately. In addition, this procedure eliminates most interfering substances from sample matrices efficiently. The method was validated using mixture of three groups of standards, and applied for the analysis of environmental samples. This method can be used to simultaneously analyze PCBs, PCDD/Fs and PBDEs in a single extracted sample.

\section{Acknowledgements}

This work is financially supported by National Basic Research Program of China (2003CB415001) and Hitech Research and Development Program of China (2002AA601011). Jiang and Cai would also like to acknowledge the Distinguished Young Scholar Award of the National Science Foundation of China (\#20329701).

\section{References}

[1] H. Fiedler, Chemosphere 32 (1996) 55.

[2] R.E. Alcock, A.J. Sweetman, K. Prevedouros, K.C. Jones, Environ. Int. 29 (2003) 691.

[3] S. Safe, Crit. Rev. Toxicol. 24 (1994) 87.
[4] G. Chen, A.D. Konstantinov, B.G. Chittim, E.M. Joyce, N.C. Bols, N.J. Bunce, Environ. Sci. Technol. 35 (2001) 3749.

[5] E. Eljarrat, A. De La Cal, D. Larrazabal, B. Fabrellas, A.R. FernandezAlba, F. Borrull, R.M. Marce, D. Barcelo, Environ. Pollut. 136 (2005) 493.

[6] G. Falcó, A. Bocio, J.M. Llobet, J.L. Domingo, Food Chem. Toxicol. 43 (2005) 1713.

[7] A. Fernandes, S. White, K. D'Silva, M. Rose, Talanta 63 (2004) 1147.

[8] S. Litten, D.J. Mcchesney, M.C. Hamilton, B. Fowler, Environ. Sci. Technol. 37 (2003) 5502.

[9] C. Pirard, E. De Pauw, J.-F. Focant, J. Chromatogr. A 998 (2003) 169.

[10] E. Eljarrat, A. de la Cal, D. Barcelo, J. Chromatogr. A 1008 (2003) 181.

[11] E. Eljarrat, D. Barcelo, Trends Anal. Chem. 23 (2004) 727.

[12] M. Alaee, in: R. Clement, B. Burk (Eds.), Proceedings of the Fourth Biennial International Conference on Monitoring and Measurement of the Environment, Toronto, 2002, p. 309.

[13] US EPA, Method 1613, 1997.

[14] US EPA, Method 1668 Revision A, 1999.

[15] Q. Zhang, G. Jiang, Chemosphere 61 (2005) 314.

[16] M.L. Hardy, Chemosphere 46 (2002) 717.

[17] A. Martínez, M. Ramil, R. Montes, D. Hernanz, E. Rubí, I. Rodríguez, R. Cela Torrijos, J. Chromatogr. A 1072 (2005) 83.

[18] P. Hess, J. de Boer, W.E. Cofino, P.E.G. Leonards, D.E. Wells, J. Chromatogr. A 703 (1995) 417.

[19] J.A. Dunn, K.B. Holland, J.R. Jezorek, J. Chromatogr. 394 (1987) 375.

[20] R.P. Eganhouse, Int. J. Environ. Anal. Chem. 26 (1986) 241.

[21] E. Aries, D.R. Anderson, N. Ordsmith, K. Hall, R. Fisher, Chemosphere 54 (2004) 23.

[22] L. Ramos, L.M. Hernandez, M.J. Gonzalez, J. Chromatogr. A 759 (1997) 127.

[23] R.R. Chang, W.M. Jarman, J.A. Hennings, Anal. Chem. 85 (1993) 2420.

[24] F.E. Ahmed, Trends Anal. Chem. 22 (2003) 170.

[25] K. Saito, A. Sjödin, C.D. Sandau, M.D. Davis, H. Nakazawa, Y. Matsuki, D.G. Patterson Jr., Chemosphere 57 (2004) 373. 